\title{
Insights Regarding the Applicability of Semiotics to CSR \\ Communication Research
}

\author{
Kemi C. Yekini
}

\section{Overview}

In the last decade, CSR debate seem to have shifted from the question of whether to report on CSR activities to what should be the actual content of the reports. Fresh concerns are being expressed about the scope, quality and authenticity of the reports. This could be borne out of increased awareness and reporting of it in annual reports. Consequently, scholars such as Davison (2007, 2011); Macintosh \& Baker (2002) have called for a 'linguistic turn' in evaluating such disclosures. The linguistic turn as defined in Macintosh and Baker (2002:185) refers to "the idea of treating the phenomena ... as a text and analysing it for its textual properties..." The argument is that corporate disclosures should be seen as polysemous texts or languages that are capable of being misinterpreted. In this way, firms will be inclined to give more consideration to the contents and hence quality of the reports. Davison (2011) argued that what is being interpreted is the language itself rather than the intended meaning of the author as each language involves particular interpretation uncommon to other languages and that such interpretation is interrelated with a variety of knowledge and experiences and hence is capable of influencing thoughts and perceptions in different ways. This chapter explores the use of a linguistic based theory and analytical tool - Semiotics as a research methodology in evaluating the content and the quality of CSR reporting. The argument of this chapter is that given the narrative nature of CSR reports (CSRR), research into the content and quality of CSRR can be better achieved with a linguistic based framework.

\section{Introduction/Context}

Since the CSR communication research lacks a fundamental theoretical conception and methodology, researchers from variety of disciplines have approached their work from their individual and often conflicting perspective. The result is that the last decade witnessed enormous and conflicting studies on the content of CSRR. Over the years the findings from the various studies have remained unintegrated and often pedestrian or overlapping. However as 
debates have now moved from the question of whether to report on CSR activities to what should be the scope and quality of the reports, the importance of establishing a consensus and cardinal methodological base for the CSR communication research cannot be overemphasised. The debates on these issues, (Beattie, McInnes, and Fearnley, 2004; Beretta and Bozzolan, 2004, 2008; Botosan, 2004; Yekini and Jallow, 2012; Yekini, Adelopo, Andrikopoulos, and Yekini, 2015) basically, centres on the best measure of CSRR generally, that is whether to measure CSRR in terms of its quantity or its quality and if the latter, what should be the best measure for quality. Nevertheless variety of definitions and measurements of disclosure quality exists in the literature, while the debate centres on the best way of measuring disclosure quality

Consequently various methods of measurement have been used in literature as a measure of disclosure quality, while some have used analyst ratings (Hasseldine, Salama, \& Toms, 2005; Toms, 2002); others have constructed their own index (Beattie et al., 2004; Botosan, 2004; Freedman \& Stagliano, 1992, 1995, 2008; Walden \& Schwartz, 1997). Beattie et al. (2004) categorized the different approaches used in literature into two, namely subjective analyst ratings studies and semi-objective studies. Studies adopting semi-objective approaches include thematic content analysis studies, readability studies, linguistic analysis studies and disclosure index studies (see Beattie et al., 2004:208-213) for detailed review of these studies and approaches.

Furthermore in measuring the quality of CSRR some scholars (Gray, Kouhy, \& Lavers, 1995; Guthrie \& Parker, 1990; Guthrie, Petty, Yongvanich, \& Ricceri, 2004; Hackston \& Milne, 1996) included the quantity of disclosure along with other criteria, such as location and evidence, while some authors simply used quantity alone as a proxy for quality. These authors do not distinguish between the quantity and quality of disclosures, arguing that the quantity of information is capable of influencing the quality. On the other hand, some other scholars (Walden and Schwartz, 1997; Freedman \& Stagliano, 1992, 1995, 2008; Tom, 2002; Beattie et al., 2004; Hasseldine et al., 2005) distinguished between quality and quantity of disclosures arguing that quantity alone will not be an adequate measure of quality and that measuring the quality of disclosure is much more important than the quantity as the quality conveys the meaning and importance of the message.

To this end, Beattie et al. (2004) argued for the development of a comprehensive disclosure profile that could serve as a practical tool for measuring disclosure quality and suggested a four-dimensional framework for measuring quality, namely, the amount of disclosure spread across topics and three attributes of the information, namely, historical/forward-looking; financial/non-financial and quantitative/non-quantitative while 
describing the quality of narrative disclosures as a complex and "multi-faceted concept" (p.227). In addition they introduced a computer-assisted methodology for the applicability of the framework. Arguably however, while commending the holistic approach of Beattie et al., (2004), it is instructive to note that their approach, apart from the introduction of computerassisted methodology, is not entirely different from previous methods of measuring CSRR quality documented in extant literature. For example Guthrie and Parker (1990); Gray et al. (1995); Hackston and Milne (1996); Guthrie et al. (2004) all included in their measurement of CSR information quality, the volume of disclosure spread across theme, the financial/nonfinancial and quantitative/non-quantitative attributes, while Walden and Schwartz (1997); Freedman \& Stagliano, $(1992,1995,2008)$ also considered the timing (i.e. historical/forwardlooking attributes) in the construction of their index.

Accordingly Botosan (2004) suggested that as there are no generally accepted frameworks of disclosure quality, researchers could employ the guidelines provided by the International Accounting Standards Board (IASB) and the Financial Accounting Standards Board (FASB), arguing that such guidelines gives a better foundation for the development of a framework of disclosure quality. The IASB and FASB stated that information disclosed in annual reports can only be useful to economic decision makers if they possess the attributes of: (1) understandability, (2) relevance, (3) reliability, and (4) comparability. To this end Botosan (2004) offered a definition of quality as;

Quality = f (understandability, relevance, reliability, comparability)

She opined that since this framework is produced by the standard setters, it is reflective of a more generally accepted definition of disclosure quality. However, even if we accept Botosan's framework, the operationalization of these attributes becomes an issue as observed by Hooks and van Staden (2011), who, adopting Botosan's approach, found that although it was possible to assess the understandability, relevance and comparability of the information, the reliability was very difficult to assess. Consequently, while some studies have continued to raise fundamental questions as to the quality and authenticity of CSRR (Aras and Crowther, 2009; Burritt and Schaltegger, 2010; Cho, Roberts, and Patten, 2010; Yekini and Jallow, 2012), others have examined it from the point of view of stakeholders concerns, thus examining a cross-country and developing-economy comparison (De Villiers and van Staden, 2010) and its relationship with accountability (Adams, 2004; Cooper and Owen, 2007), while other scholars have called for a literary approach to examining the reliability of the information (Aras \& 
Crowther, 2009; Bebbington, Larrinaga-González, \& Moneva-Abadía, 2008; Crowther, 2002; Davison, 2011; Yekini \& Jallow, 2012; Yusoff \& Lehman, 2009). These scholars argued that to investigate the reliability and quality of disclosures of this nature, it should be subjected to textual analysis which is an active way of decoding the messages in the text by the reader. Bebbington et al. (2008:353) therefore encourage CSR communication researchers that the "... focus on linguistic strategies, ..., may be especially appealing if analysis of reporting moves towards examining discourses rather than quantitative measures of disclosure". In this chapter the authors are therefore motivated to explore and develop a semiotic framework for measuring the reliability and quality of CSRR grounded in literary theoretical underpinnings.

Previous studies (Fiol, 1989; Macintosh, Shearer, Thornton, and Welker, 2000; Crowther, 2002; Macintosh and Baker, 2002; Yusoff and Lehman, 2009; Davison, 2011) have attempted the application of literary perspectives in their interpretation of corporate and CSR reports. Fiol (1989) examined the semiotics of CEOs' letters in annual reports and was able to establish that these letters revealed the link between organisational beliefs and strategic behaviour which has hitherto been very difficult to capture with conventional research methods. Macintosh et al. (2000) and Macintosh and Baker (2002) drew on radical semiotics and Baudrillard's orders-of-simulacra theory to investigate the reality of accounting information and concluded that a literary theory perspective gives a different view of the nature of accounting and accounting reports. Similarly, Yusoff and Lehman (2009) found semiotics very useful in "making sense" (p.241) of corporate reporting practices in their investigation and comparisons of corporate reporting practices in Malaysia and Australia. Also Crowther (2002) investigated the binary opposition between corporate reporting and environmental reporting using the semiotic stage and found that corporate performance in both financial and environmental dimensions cannot be dissociated from one another. He found that a company performing well financially was found to be performing well in both dimensions, which appears contrary to the findings of studies adopting conventional research methods such as Hackston and Milne (1996); Ho and Wong (2001); Hasseldine et al. (2005) who found no relationships between profitability and CSRR. In this chapter, we depart from others whose focus is on evaluating the intended meaning of the reports by viewing the reports from the standpoint of the audience/users.

\subsection{Towards developing a theoretical framework for CSRR-Quality measure}

We developed the our CSRR-Quality framework by employing both the Preston and Post (1975); Preston (1975) and the Wood \& Jones (1995) Firm/Society relationship models; see Figures 1 and 2 for representations of these models. Preston and Post (1975), looking at it 
from the point of view of the organisation, developed a framework for managing social issues. In the framework, they recognise the fact that corporations would: first, be aware and/or recognise a social issue (i.e. establish an expectation-gap); secondly, the corporation plans on solving the issue and incorporate such plan into its corporate goal; thirdly, the corporation responds in terms of policy development, and finally implementation of the policy.

Figure 1: Corporation/Society relationship - Preston and Post (1975) and Preston (1975) perspective

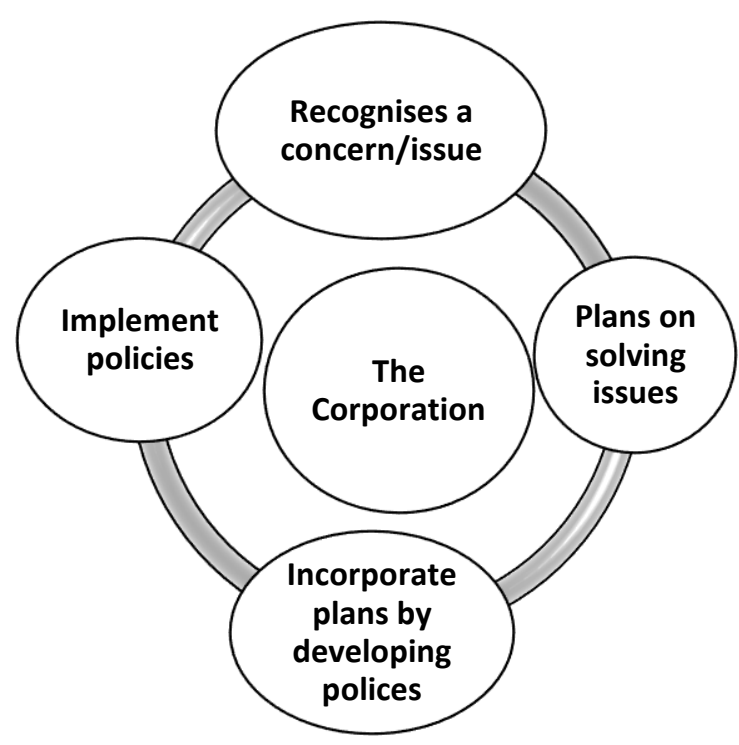

Wood and Jones (1995) on the other hand argued that the role of the society in the stakeholder system is first and foremost to set the expectation gap. It is this expectation gap that is being addressed by management through corporate actions and consequently, corporate disclosures/reporting. Corporate reports such as CSRR are invariably seen as the language of business with which the firms communicate with the society. This then enables the society to evaluate the outcome of corporate actions in addition to experiencing the effect of corporate actions. Since CSR is regarded as a corporate action intended to meet the expectation of the society, then its communication via CSRR or disclosures in annual reports will signal adherence to societal expectations. Therefore as beneficiaries the society should be the best judge of the quality of such reports/disclosures.

Wood and Jones (1995) pointed out that in order to achieve a better understanding of the legitimisation process, the question "To whom does corporate social performance make a difference?" (Wood and Jones, 1995:241) must first be answered. They describe this as the missing link in understanding the overall relationship between corporations and society. Nevertheless they opined that understanding the CSRR phenomenon from a stakeholder theory perspective involves identifying the particular stakeholder group involved. They therefore 
proposed a corporation/stakeholder model, where multiple stakeholders' expectations, effects, evaluations and behaviours are well defined. This, they argued, would allow for a better understanding of how the relationship between the corporation and the stakeholder arises in the first place and what led to the expectation gap being addressed by management through disclosures. The knowledge of such a relationship would lend itself to the development of relevant measures of investigation while taking into consideration the role of the stakeholder in setting expectations, experiencing the effect and evaluating the outcome (Wood and Jones, 1995). We conjecture that the Wood and Jones (1995) model, when applied in conjunction with the Preston (1975) model could form the basis for the application of the Greimas semiotics framework and thus, help to define the components necessary to create a semiotic model for the evaluation of CSRR quality.

\section{Figure 2: Corporation/Society relationship - Wood and Jones (1995) perspective}

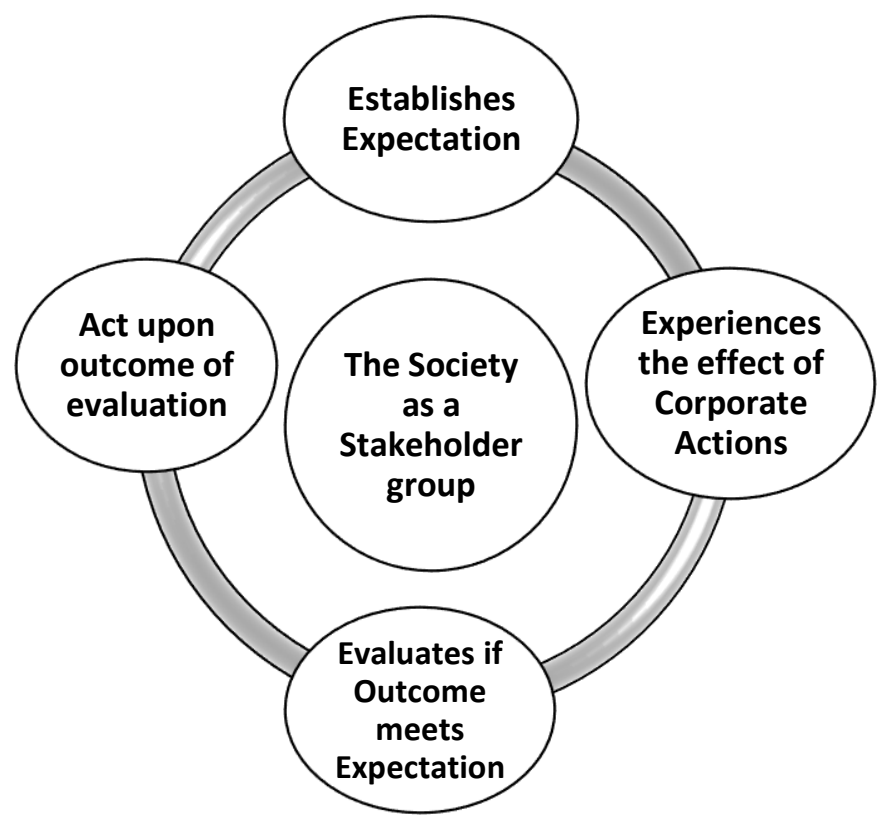

Following the Wood and Jones (1995) model, since the society is responsible for setting the expectation gap, we argue that they should also be in a better position to evaluate whether or not the outcome of the corporate plans/actions (CSR activities) meets societal expectations. This is consistent with the viewpoints of Price and Shanks (2005) who argued that, the users of data; CSR reports in this case, should constitute the final judge of the quality of such data/reports (Price and Shanks, 2005). In other words, to unearth the reliability and quality of CSRR, we argue that the reports should be viewed and interpreted from the perspective of the audience (i.e. the society that sets the expectation-gap in the first place) since they are in a better 
position to determine whether their expectation has been met. To this end, we incorporated the evaluative stage into our framework following the principles of the Greimasian canonical narrative schema (discussed further in section 4.2). In the next sub-section we explore corporate reporting as a language capable of influencing the reader. This will give us further insights that would enable us to better understand the place of semiotics in the development of the CSRRQuality framework.

\subsection{Corporate reporting as language of business}

The fact that language influences thinking and hence perception has been well argued by renowned scholars in the field of linguistics and psychologists such as Gumperz and Levinson (1996); Lucy (1992, 1997). Lucy (1997) classified the manner in which language can influence perception into three parts; semiotic or semiology ${ }^{1}$, structural, and functional ${ }^{2}$. Of particular interest to this chapter is the semiotic effect of language on perception. The argument is that when language is used in a particular way it may influence thinking and hence have effect on perception (Lucy, 1992, 1997).

Consequently Jain (1973) and Belkaoui (1978), drawing from the "Sapir-Wharf

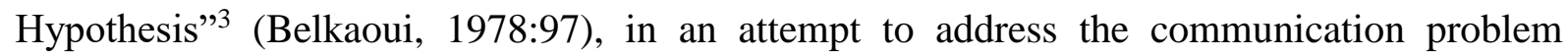
between corporations and stakeholders, argued that as language of business, information contained in corporate annual reports can be read or spoken like any other language. This followed the argument put forward by Sapir and Whorf that each language involves particular interpretation uncommon to other languages and that such interpretation is interrelated with a variety of knowledge and experiences and hence is capable of influencing thoughts and perceptions in different ways, (Jain, 1973; Belkaoui, 1978; Gumperz and Levinson, 1996).

As language of business, scholars such as Jain (1973); Belkaoui (1978); Cooper \& Puxty (1994); Macintosh et al., (2000); Macintosh and Baker (2002); Macintosh (2003); McGoun, Bettner, and Coyne (2007) argued that corporate disclosures whether contained in annual reports, press releases, accounting magazines or even a separate CSR reports and in whatever

\footnotetext{
${ }^{1}$ The term semiotics is more widespread in English-speaking countries, while semiology is preferred by the French linguists. However in this chapter the term semiotics has been used.

${ }^{2}$ The functional use of language developed from the concept of functional fixation. This concept according to Jain (1973) state that once a person relates a meaning to a particular phenomenon or event through past experience, this meaning becomes fixed in his head and is related to subsequent phenomena or event irrespective of alternative meanings or causes of that event.

${ }^{3}$ Also known as the Linguistic Relativity Hypothesis. The hypothesis historically developed through the works and propositions of Edward Sapir (1884-1939) and Benjamin Lee Whorf (1897-1941). Although most of these works were not published, they later became the source of controversial debate among anthropologists, psychologists, and linguists (Gumperz and Levinson, 1996).
} 
format, whether quantitative, narratives, images, graphs or in tables all represents means of communication. They therefore emphasised the need for a 'linguistic turn' in drawing meanings from such disclosures, arguing that corporate disclosures should be seen as texts capable of being interpreted like any other language. Davison $(2007,2011)$ supported these views and argued that what is being interpreted is the language itself rather than the intended meaning of the author. Consequently, since as text, they have polysemous characteristics, Price and Shanks (2005) argued that “... information consumers (i.e. internal or external users of organisational data) are the final judge of quality" (Price and Shanks, 2005:659).

However in an earlier study Jain (1973) argued that as languages represent phenomena in the real world so does corporate disclosures in the business world. Therefore he described accounting rules as financial grammar and considered it as analogous to grammatical structure in linguistics and therefore examined its effect on the perception of the listeners (i.e. the readers/users) of such information. He found that accounting information affected decision making. Similarly, Belkaoui (1978) argued that the lexical characteristics and grammatical rules of accounting will affect the linguistic and non-linguistic behaviour of users of accounting information. He argued that the use of accounting language in different ways by different users can affect its information content and therefore influence behaviour in different ways. Moreover, Macintosh and Baker (2002) illustrated that as the language of business, the claim that accounting information represents an objective reflection of reality may only be sustained when such information are investigated for their narrative qualities. Davison $(2007,2011)$ argued that accounting and finance researchers should employ linguistic-based theories such as semiotics in accounting and finance research, arguing that economic-based theories have lost power in predicting social phenomena.

In this chapter, we present a framework for measuring CSR information quality based on semiotic theory. Specifically we adopt the Greimas semiotics approach. Semiotics as a wellestablished linguistic theory spanning over ten decades has been proved to be suitable for analysing sign related communications (Price and Shanks, 2005). Hence it is apt as a theoretical framework for defining criteria to establish the reliability and quality of information. The aim of this chapter is to provide an approach for measuring the reliability and quality of CSRR that is both theoretically grounded and practical and that can serve as a basis for further research in CSRR research. The framework can also serve as a theoretical tool and procedure for measuring the quality of CSRR. Therefore, the focus of this chapter is on the use of the Greimas semiotics tools as a suitable theoretical technique for determining the criteria with which to measure CSR information quality. In the next section, we review semiotic theory; it's origin, development 
and criticisms. This is followed by section 4 with detailed discussion on the Greimas and Barthes semiotics. The section starts with a comparison of the Barthesian and the Greimasian semiotics, followed by detailed description of the processes involved with the development of the Greimas CSRR-Quality semiotics framework. Finally section 5 summarises and concludes the chapter.

\section{Semiotics and the semiotic theory}

\subsection{The Saussure Semiology4 (Semiotics)}

Semiotics ${ }^{5}$ is, simply put, the study of signs and is based on semiotics theory. The foundation stone of semiotics was laid by Swiss linguist Ferdinand de Saussure (1857-1913) through his lecture 'Course in General Linguistics' published in 1916 after his death (Barthes \& Duisit, 1975). Semiology (as known by Saussure) actually developed out of linguistics which is the scientific study of languages and has since expanded to conceptualize the general study of signs (Crystal, 1987). Saussure described semiology as a science of signs encompassing any system of producing signs which constitute some form of signification. Such signs which could be in the form of behaviour, a pattern of doing things, an image, an object, a sound or even a name is usually intended as a form of signifier or signal carrying many more messages than the written words (Barthes \& Duisit, 1975). Eco (1976) therefore summed up that semiotics is concerned with anything that can be taken as a sign, including an act or behaviour by an individual or a corporation.

According to Saussure, the linguistic sign does not unite a thing and a name but rather a concept and the sound, image or gesture (Saussure, 1983). For instance, the colour red could mean much more than being just one of the primary colours, but could connote a range of apparently differing emotions. For example, it could denote anger, violence or war. It could also mean stop, danger or emergency. Better still, it could denote energy, strength or power as well as passion, desire or love. The meaning assigned to it at any point in time therefore depends on the circumstances surrounding its use, any other sign that goes with it, as well as the experience and knowledge of the interpreter. If we apply Saussure's model of a sign - the

\footnotetext{
${ }^{4}$ While, Saussure refers to it as Semiology, Peirce refers to it as Semiotics.

${ }^{5}$ Semiotics is associated with the structuralist philosophical stand point. Structuralism is a $20^{\text {th }}$ century philosophical school of thought and although it has its roots in interpretivism, while human beings are the central focus of the interpretivist, the structuralist, decentres humans and rather focuses on the structures of which humans are seen as elements (Bryman, 2008).
} 
signifier and the signified - the colour red represents the signifier while the concept of love, stop or danger represent the signified as shown diagrammatically below. In other words the Saussure model divides a sign into two inseparable components - the signifier and the signified - while the relationship between the two is the signification.

\section{Figure 3: Saussure's Dyadic Model of the sign}

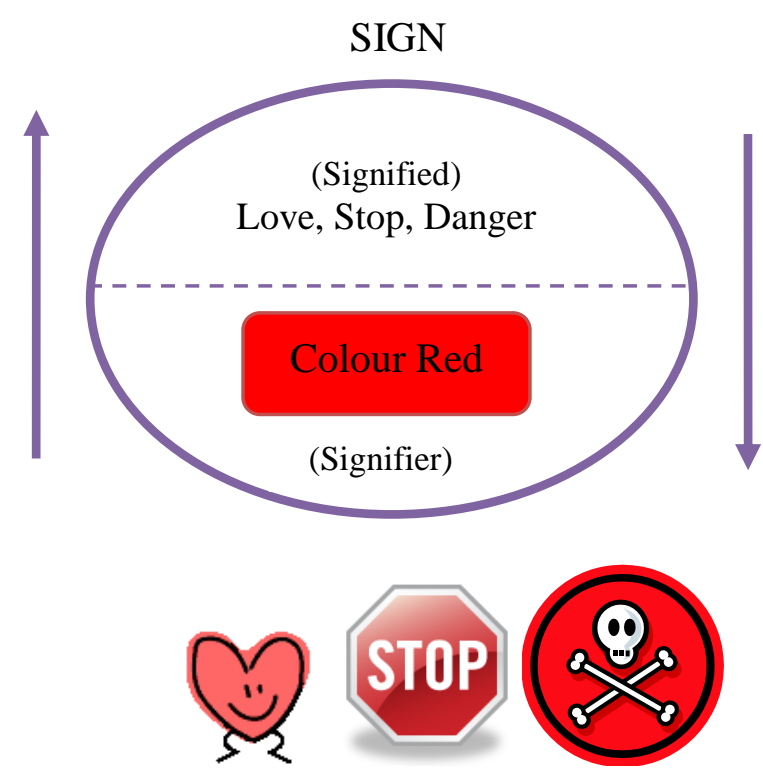

Adapted from Chandler (2007)

\subsection{The Peirce Semiotics}

At about the same period as Saussure, an American philosopher, Charles Sanders Peirce (1839-1914), developed the theory of semiotics which he defined as a doctrine of signs (Chandler, 2007). To Peirce, a sign is anything which stands for something in some respect or capacity to somebody. Accordingly Peirce considered a sign as having three elements: iconic, symbolic and indexical; as against the two components of Saussure's signifier and signified. Iconic signs are those that bear close resemblance to the signifier. For instance a picture of a school building in support of a community involvement project disclosed in an annual report may be iconic, if the narrative also indicate educational support. However the same picture may be seen as symbolic (i.e. used as a mere symbol of involvement in community activity) if no mention is made in the narrative that the company is actually involved with the building of a school. A sign is indexical if the signifier is usually associated with a particular signified; for example a smoke could be seen as signifying fire. Peirce argued that all social practices can be 
seen as signs (representamen) which stand for something (its object) to somebody (it's interpretant) in some respect or capacity (its ground) (Peirce 1931-58).

Figure 4: Peirce's Triadic Model of the sign

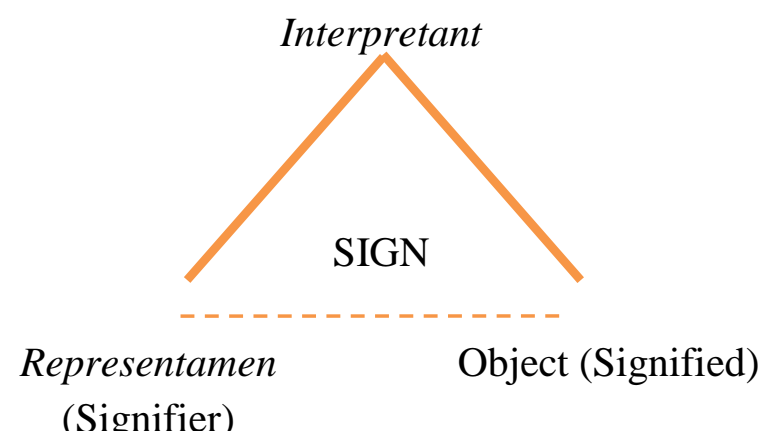

(Signifier)

Adapted from Chandler (2007)

The triadic interactions of these terms, known as semiosis, refer to the process of signification which is quite different to the dyad relationship of Saussure's signifier and signified. Peirce's triadic model is usually represented by a triangle (see Figure 4) showing the triad relationship (Chandler, 2007). Peirce proposes various possible combinations of these triadic relationships depending on the type of sign and ends up with several classes of signs (Hawkes, 2004). Arguably therefore, Peirce's analysis appears to extend the work of Saussure by enumerating different types of signs, how they interact and what rules govern each set of signs to form signification. While Saussure's model made no reference to any external reality outside the sign system, but simply identified the hidden binary oppositions in the signs in order for signification to occur, Peirce's model made reference to an interpretant or referent which is beyond the sign and is sign in itself (Chandler, 2007), thus leading to series of signs the collective presence of which constitutes signification. Therefore, in Peirce's model, signification is seen as a generative process (Floch, 1988).

\subsection{Further developments in Semiotics}

Since the death of these two founding theorists of semiotics, semiotics has undergone different stages of development; notable works among contemporary Semioticians are Morris (1946); Jakobson (1942, 1960); Barthes (1967, 1972, 1973); Lévi-Strauss (1972); Eco (1976); Greimas (1983, 1987); Sebeok (1977, 1994) and Baudrillard (1988). Barthes introduced different orders of signification (Barthes and Duisit, 1975). He refer to the first order signification as "denotation" which, simply refers to the iconic meaning of a sign in which the 
photograph of a new school building within a community system could simply mean a school or a place of learning. The second order signification, referred to as "connotation", is when further interpretation is given to the photograph. Such connotation will normally be influenced by our knowledge of the financier of the school building as well as our experiences and knowledge of the ideological and political phenomenon within the community where the building is located. This is referred to as myth by Barthes. However taking into consideration the on-going debate on CSR and the current trend among corporations to be seen as socially responsible, a further meaning or myth may be activated from the photograph going by Barthes' mythological analysis. The photograph of a new school building within a community displayed on the front page of a CSR report or the annual report of a multinational company may connote a second order signifier, signifying that the multinational company is involved in community development or could be said to be socially responsible.

Semiotics is often used as a form of textual analysis. Text here could be in the form of words, images, gestures or sounds, recorded in a particular medium of communication which will be independent of both the sender and the receiver; the message could be in writing, audio or video recording or an image (Chandler, 2007). Semioticians believe that an analogy can be drawn between languages and signs. In other words signs in whatever form (gestures, sounds, pictures or TV films) are like languages or texts that can be read like the written word, while the users of such texts are referred to as readers (Crystal, 1987). Reading a text is an active way of decoding the messages in the text by the reader. In the same way the reader of a sign can decode the signification of that sign within the repertoire offered by the sign (Fiske, 1987).

Semiotics as a science emphasises the fact that social practices are expressed like languages. Hence, as languages are a structured system of symbolic representation developed out of culture, the meaning we give to any social practice is also developed out of our cultures and therefore has symbolic cultural meaning and values (Kristeva, 1973). Billington (1991) asserted that all forms of social practice have the potential to mean something with the meaning finding its route from the codes used within a particular cultural environment. For example in Eastern culture the refusal of a woman to wear the veil could signify refusal of Islamic laws and as such she stands the risk of being prosecuted under Islamic law, whereas in Western culture whether a woman wears the veil or not is a matter of choice and may either signify nothing or in the present times, if she is from an Eastern background, may signify fundamentalism. In other words the codes used in the sign systems of different cultural settings express and support the social organisation of those cultures. To this end the meaning we read 
to a sign cannot be independent of the ideological and political situation in existence (Billington, 1991).

Accordingly Saussure argued that for signs to be useful as a tool of communication, the sign system will have cultural meaning and values incorporated in it, that is, the value of a sign is culture-specific since it is developed out of culture. Therefore, the values of our culture are incorporated into the signs we use. In other words the meaning given to a particular sign is a function of the reader's cultural knowledge and experience of the system within which the sign developed (Saussure, 1983; Chandler, 2007). Consequently, Saussure argued that signs can only give signification where they enjoy relational values. That is, the value attached to a sign is as a result of its relationship to other similar values and the fact that one event follows after another, otherwise signification would not exist (Berger, 2005). Saussure refers to these relational values as syntagmatic and paradigmatic relations as we have them in the text of languages where one word would have to come after another for us to make a meaningful sound or statement.

\subsection{Criticisms of Semiotics Theory}

One of the popular criticism of semiotics as a study of signs is that, as it concentrated mainly on the generation of meanings from signs, it totally ignored the quality of such signs (Berger, 2005). Furthermore, it ignored the institutional frameworks, and the social, economic and the political context within which the sign was produced (Chandler, 2007). In other words, semiotics is only concerned with 'how' the sign generates meanings rather than answer the question: 'why' produce the sign in the first instance? (Slater, 1997:141). Accordingly, the structuralist semioticians are criticized for the way texts are related to their own structures. Buxton, (1990) argued that text ought to be related to other things outside its own structures, while Chandler (2007) argued that since structures are not the causes of producing the sign, semioticians should not only be concerned with structural signification but also why signs are socially produced, while maintaining that the ontological arbitrariness between the signifier and the signified in the structural context may not apply in the social or political context. Furthermore, work on semiotics has centred on establishing its scope and fundamentals. Chomsky (1968) criticized the fundamental assumption of semiotics that all social practices are like written texts capable of being read and interpreted; while commenting on the work of LéviStrauss on the kinship systems, he argued that nothing was documented to show any resemblance to language in the study. 
Although Saussure's semiology is accepted as the starting point, both the Saussure and Peirce models have received criticism and have undergone various developmental stages (Jakobson, 1960; Lévi-Strauss, 1972; Barthes, 1973; Greimas, 1983). Notwithstanding the criticism, however, semiotics has been applied to empirical studies by scholars in various fields of study basically testing the semiotic principles. However, while the early semioticians (Saussure, 1983; Peirce, 1931-58; Propp, 1958 and Barthes, 1967) were more concerned with seeking deep structures beneath the surface of a phenomenon, modern semioticians (Greimas \& Courtés, 1982; Cooper and Puxty, 1994; Macintosh and Baker (2002); Davison (2007, 2011); Crowther, 2002; Yusoff and Lehman, 2009) are more concerned with the use of signs to shed more light on specific social phenomenon (Chandler, 2007).

Chandler (2007), emphasising the importance of semiotics, asserted that semiotics is very useful if the task is to look beyond the content of the text. He pointed out that semiotics reveals the role of humans in the construction of reality and the fact that meaning is not 'transmitted' to humans through books, computers or media, but that humans are actively involved in the creation of meaning through a complex interplays of codes and conventions. He remarked that "Becoming aware of such codes is both inherently fascinating and intellectually empowering” (Chandler, 2007:11). He argued further that the study of signs helps to define reality as it is represented, since reality as presented in the social world may not be what it appears to be; accordingly a particular representation may symbolically stand for something else. This echoes Belkaoui (2004) argument, in his book on accounting theory, that a statement believed to be true or false should still be proven as true or false before it is accepted as the truth or false. Similarly, Eco (1976) argued that to establish reality, one must be able to distinguish whether the sign is actually telling the truth or a lie about the phenomena, since anything that can be used to communicate the truth can also be used to communicate lies.

However, while semiotics as a method of analysis is well established in France and Italy, the drive for its use has only just begun in the UK and other countries (Berger, 2005). For instance its use in the UK may be traced to the work of the Centre for Contemporary Cultural Studies (CCCS) at the University of Birmingham between 1969 and 1979 (Chandler, 2007). Similarly semiotic principles and techniques have been scantly applied to management and social research generally; nevertheless its use is gradually gaining ground. Although its application in management research has largely concentrated on Marketing and Corporate Communication studies (Burgh-Woodman and Brace-Govan, 2008; Corea, 2005; Kameda, 2005; Otubanjo and Melewar, 2007); its use in management research is fast growing as studies on Organisational Behaviour (Hancock, 2006); Accountability and Management research (Bell, 
Taylor, and Thorpe, 2002; Cooper, Dimitrov and Rau, 2001; Fiol, 1989; Lindblom and Ruland, 1997; Joutsenvirta \& Usitalo, 2010); Accounting research studies (Cooper and Puxty, 1994; Macintosh and Baker, 2002; McGoun et al., 2007; Davison, 2007 \& 2011) and in fact Corporate Social and Environmental Reporting studies (Crowther, 2002; Yusoff and Lehman, 2009) have all began a skeletal adoption of its use.

\section{Greimas semiotics}

\subsection{Greimas vs. Barthesian Semiotics}

As an emerging research technique, semiotic has developed into different strands depending on the sort of sign system being studied (Chandler, 2007), while different school of thoughts have also emerged (Propp, 1958; Jakobson, 1960; Greimas, 1983; Lévi-Strauss, 1972; Barthes, 1973). However these schools of thoughts are broadly grouped into the paradigmatic and the syntagmatic techniques, with the sign system being the distinguishing features. Consequently semioticians and those adopting semiotics as technique of analysis have often analysed text according to the structural relationship inherent in the text using either syntagmatic or paradigmatic approaches.

A sign enjoys syntagmatic relations where signification occurs as a result of the sequence of events that made up the narrative or story, while in paradigmatic relations signification occurs as a result of the association of the sign with other signs within the narrative. Therefore the Saussure model, discussed earlier, may be said to be paradigmatic in nature while the Peirce model is syntagmatic in nature. While the Saussure model emphasises the natural language (that is, words) as the sign system, the Peirce model emphasises the sequence of events in the narrative or groups of narratives as the sign system (Fiol, 1989; Hawkes, 2004).

The paradigmatic method follow the school of thoughts of semioticians such as Lévi-Strauss (1972) and Barthes (1973) who are more concerned about the latent structure of the text rather than what happened in the text (Berger, 2005). The syntagmatic method of analysis, on the other hand, follow the school of thoughts of semioticians such as Propp (1958) and Greimas (1983) who believes that the true meaning of a claim in a narrative can only be uncovered by identifying the pattern in which the components constituting the story are combined or structured. However, a general review of management and social research literature revealed that management and social researchers, most often, employed either the Greimas semiotics 
(Floch, 1988; Fiol, 1989; Sulkunen and Törrönen, 1997; Joutsenvirta \& Usitalo, 2010) or the Barthes semiotics (Bell et al., 2002; Davison, 2007 \& 2011). Accordingly, semioticians adopting the paradigmatic method are commonly referred to as the Barthesian semioticians, while, those adopting the syntagmatic approach are commonly referred to as the Greimas semioticians. The Barthesian semioticians are more interested in the "code through which the narrator's and the reader's presence can be detected within the narrative itself' (Barthes and Duisit, 1975:260) rather than the narrator's actions or motives or the effect the actions would have on the reader. Greimasian semioticians on the other hand defined signification as when the reader is able to uncover the truth inherent in the narrative by analysing the actions of the narrator using logical, temporal and semantic criteria (Greimas, 1983). Hence Greimasian semioticians believe that the actions or motives of the subject in the narrative are more important than the words used in describing the actions. Consequently, Greimas semiotic analysis is based on the doings of the words in the texts rather than the meaning; hence the words are seen as actants helping to describe the actions of the narrator (Hébert, 2011).

The question of whether the Greimas semiotics is superior over the Barthesian semiotics or vice-versa is an empirical question that should best be answered through empirical analysis of both techniques. Therefore, since this is beyond the scope of this chapter, we focus our discussion on why the Greimas semiotics is more suitable in the development of the CSRRQuality framework. It is instructive to note however, that whatever the approach, the interrelationship between the author, the reader and the message itself form the basis of all semiotic analysis.

Nonetheless, given that our focus is to develop a framework for measuring the content and the quality of CSRR, our interest is on the motive and actions of the narrator. This is consistent with the ideologies of the Greimas semioticians in which case the Barthesian semiotics is considered unsuitable for this purpose. Barthes and Duisit (1975) argued that once written, the author of the message as well as the motive of writing has no relevance in the interpretation of the message, which is contrary to our objective in this chapter. On the other hand further justification for Greimas semiotics is inherent in our objective, which is to unravel the veracity and quality of (the real motives behind) the reporting of CSR information and the truth inherent in the narratives. In addition syntagmatic analysis is particularly suitable for this purpose, because the disclosures are recorded corporate messages narrated in the form of folktales. They consist of stories that could be re-ordered in order to achieve a recurring structure, thereby reflecting the underlying values of the company and would be best interpreted as a whole (Propp, 1958; Eco, 1994). 
Against this background therefore, since CSRR consists of stories narrated in the form of folktales about the involvement of the corporation in developments within their community of operations, the Greimas semiotics analysis is considered the most suitable. This is because our objective as previously discussed, is to develop a framework that could be used to establish the reliability and by extension the quality of the claims made by organisations (the narrator) about their social responsibility and community involvement activities. In other words we are more interested in what actually happened in the story, which is consistent with the Greimas semiotics. This however, is contrary to the objectives of the Barthesian semioticians who adopt paradigmatic method of analysis. The Barthesian semioticians emphasise the functions of the words and their relationship to other words used in the narrative to form signification (Barthes and Duisit, 1975). Greimas semiotics on the other hand, is concerned with identifying the events (actions) within the narratives and how one event relates to another to form signification. In other words texts are analysed as sequence of events forming a narrative thus revealing the reality or what actually happened in the story (Berger, 2005).

\subsection{Greimas CSRR-Quality semiotic framework}

To develop our framework, we employed the Greimasian narrative semiotic method ${ }^{6}$ (Greimas, 1983; Greimas \& Courtés, 1982). The Greimasian narrative semiotic identifies the structural pattern in narratives and aims to clarify the necessary condition producing values through which reality may be perceived (Sulkunen \& Torronen, 1997). The method looks beyond the sign itself into the system of signification in order to uncover the truth or falseness of the sign. A narrative, as defined by Propp (1928), is a "set of interlocking signs whose meanings are determined by underlying rules that regulate how different units of text may be combined" (Propp, 1928, cited in Fiol, 1989:279). Narratives take the form of a sequence of events, actions or experiences with different parts all put together as a meaningful whole (Feldman, Sköldberg, Brown and Horner, 2004) and connected to a central purpose (Gilbert, 2002), thus reflecting the underlying values of the narrator (Propp, 1958; Eco, 1994). Accordingly narratives usually consist of a subject (the narrator or author), the object (the act or story being narrated) and the subject's competence/performance (ability to do/the act of doing) (Hébert, 2011).

The narrative semiotics method is particularly suitable for CSRR research because CSRR are recorded corporate messages narrated in the form of folktales/stories in annual

\footnotetext{
${ }^{6}$ See chapter 5 , section 5.4.3.2 for discussions on other school of thoughts on semiotic analysis.
} 
reports. The reports tell stories of the involvement of the corporation in developments within their community of operations. Thus the stories give specific details of the company's activities within its community of operation with the objectives of reflecting the underlying values of a good corporate citizen to the readership of the reports. In other words the management (of corporations) is the subject ${ }^{7}$ or author, the contents of CSRR is the object or message, while the audience consists of investors, analysts and other users of annual reports, who from time to time may need to read the content of CSRR to help inform their decision making.

\subsection{The Canonical Narrative Schema}

In narrative semiotics, narratives are analysed as a series of schemas in which the semiotic act or story may be structured into components (Hébert, 2011). The five components identified by the Greimasian Canonical Narrative Schema are;

1. The action/idea - that is, the act itself

2. Competence - what is required to achieve the act, this is described in semiotics as wanting-to-do or knowing-how-to-do,

3. Performance - the actualization of the action i.e. having-to-do and being-able-to-do

4. Manipulation - the compelling force, described in semiotics as causing-to-do

5. Sanction or reward - that is, evaluation of performance for its quality.

This may be illustrated diagrammatically as follows:

\section{Figure 5: The Canonical Narrative Schema}

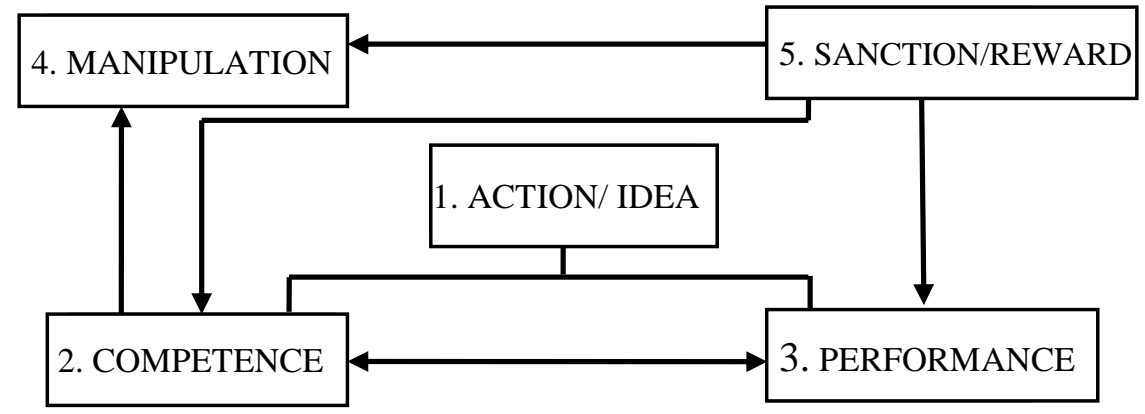

Source: Tools for Text and Image Analysis an Introduction to Applied Semiotics Analysis (Hébert, 2011:93).

Although in a typical analysis not all these components are used, but the components could at least provide the basis for a typology of discourse in a particular narrative analysis,

\footnotetext{
${ }^{7}$ Italics are used in this section for author's emphasis.
} 
depending on the trajectory of the texts and on what component is most emphasized in the narrative to be analysed (Courtés, 1991, cited in Hébert, 2011), or on what the researcher is interested in investigating. Moreover the existence of one component ultimately leads to the logical presence of the other (Floch, 1988). This confirms the fact that the structure of narratives is syntagmatic and is both temporal and spatial.

For instance the idea of getting involved in community development will usually be preceded by the manipulation component - causing-to-do, that is, the corporation must have been compelled or motivated by something, say community need or the need to legitimize its operation, before deciding to get involved (i.e. competence or wanting-to-do) in community development (i.e. performance). In other words the competence and performance components follow simultaneously, thus indicating that two components may be implicit in one. Hébert (2011) argued that the relationship between competence and performance is that of "reciprocal presupposition" in which case competence will necessarily mean performance and whenever there is performance this would have been preceded by competence (Hébert, 2011:96). Furthermore the performance component is ultimately followed by the sanction component which is an evaluative component.

\subsection{The Framework}

To develop our framework, we employed a two-phased narrative analysis technique. The first phase will involve the identification of the modality of the narratives based on the narrative schema discussed above. The second phase will identify the cognitive perspective (Maddox, 1989), developed into veridictory positions using the semiotic square of veridiction in order to determine the ontological status. However before proceeding into the description of each process, it is imperative to discuss the creation of modality. The modality refers to the structure evaluating the state of affairs of the subject (Sulkunen \& Torronen, 1997): that is, the being and doing of the subject of the narratives (Fiol, 1989) and whether or not reality may be constructed.

Modality may be viewed from two perspectives: the morphological and the semantic. The morphological perspective views modality from the grammatical angle that is, the interconnectivity and interdependence of the words used in the narrative (Sulkunen \& Torronen, 1997), while the semantic approach views modality from the perspective of the content of the narrative and their signified (Hébert, 2011). The semantic approach is considered relevant to our framework since the values imputed to a phenomenon by the components of the narrative schema enumerated above do not make up the meaning of the action itself, nor do the 
grammatical relationships of words reveal the reality of the phenomenon (Sulkunen \& Torronen, 1997; Hébert, 2011). Conversely, in the semantic plane of texts, values are imputed when the dialectics, that is, the tensions between the processes and the actors involved in them along with the logical sequencing of the content of the narratives are subjected to modal evaluation known in semiotics as dialogics. Modal evaluation is to determine whether the semiotic act can be said to be true or false (known as veridictory status) or whether the semiotic act can be situated in one of the three worlds of the semantic universe, that is: the actual world (what is), the counterfactual world (what is not) or the possible world (what could be). This is known in semiotics as the ontological status i.e. relating to existence or ontology, hence the ontological status may be: real, unreal or possible/doubtful (Hébert, 2011).

Consequently to understand social reality, a semantic unit is usually formulated as a logical proposition and then evaluated on its veridictory and ontological status (Hébert, 2011). For instance, the proposition (the Sky is blue), may be assigned a true or false value (the veridictory status) which will then determine the world in which it should be situated (i.e. actual, counterfactual or the possible world). So if the proposition - the Sky is blue - is say true, then it is situated in the actual world and assigned an ontological status of real. Conversely, if it is false or a combination of true and false, it might be situated in the counterfactual or the possible world. Furthermore, the components of the canonical narrative schema enumerated above suggested that to perform a semiotic act, an actor or narrator is not only motivated by something, but should also exhibit the desire and willingness to perform the act. In addition the competence to perform and actual performance of the act must be evident before signification can occur. This may require the construction of several related modal structures and consequently different propositions with different degrees of certainty and therefore, may pose some challenges in determining the semantic universe and hence the ontological status.

This is so, particularly for the semiotic of CSRR, because as previously discussed in section 3.3, the values we input to a sign could be influenced by our knowledge and experience of the system within which the sign developed as well as the ideological and political situation in existence (Kristeva, 1973; Billington, 1991). For example, as with CSRR, some studies (Toms, 2002; Hasseldine et al, 2005; Yekini and Jallow, 2012) have provided evidence that the production of the reports is reputation-management motivated. This knowledge, if not well guided, may influence the values we assign to the semiotic acts in the CSRR.

However, to solve this problem, Greimasian semioticians such as Floch (1988); Fiol (1989); Sulkunen \& Torronen (1997) argued that the signification process should be generative in nature. First, it should begin with the formation of propositional discourse which develops 
from "simple deep" semio-narrative structures i.e. exhibiting abstract articulation with little condition for signification and then progress to the formation of discourses developed from "rich and complex discursive structures" (Sulkunen \& Torronen, 1997:51) which enriches signification by manifesting distinct expression of reality.

Therefore for the semiotic of CSRR, the generative process of signification requires a logical organisation of modal structures such that the juxtaposition of a set of propositions should qualify them to be situated in the same semantic universe so as to generate signification. For instance the semio-narrative structure may include simple utterances of being, that is the corporation has knowledge of a specific need within their community of operation and therefore is motivated to a further utterance of doing, which could be supplying or meeting the specific need. These thus show a transformation from the state of being to the state of doing and thus form a rich and complex discursive structure (Sulkunen \& Torronen, 1997).

Nevertheless in order to achieve a logical and comprehensive taxonomy of discourses that would reveal the underlying value of corporations and thus allow for the construction of reality, we argue that a real act of corporate citizenship should not be a one-off event but should take into consideration future development. Hence the content of such narrative reports should not only be outward-looking, but also forward-looking (Crowther, 2002). Forward-looking information, it has been argued, is capable of producing value-relevance information to the audience (Beretta and Bozzolan, 2008). Consequently in formulating our propositions, we put into perspective, both the current and future semiotic act of social responsibility and community involvement, while taking into consideration how these might be articulated in the narratives. The propositions form the basis of the modal structure upon which narrative contents will be analysed. They describe the necessity or possibility of each phenomenon. Therefore following from the Preston's (1975) framework and the Wood and Jones' (1995) model discussed earlier in section 2.1, the following propositions are typical examples that could be considered in analysing the text of CSRR using the Greimasian narrative semiotics method:

\section{Proposition 1a}

The written report on CSR shows evidence of corporations' concern or awareness of specific needs or issues identified within their community of operation. - Manipulation Component

\section{Proposition $1 b$}

The written report on CSR shows evidence of the corporations meeting the specific needs of the community within their community of operation. Competence and Performance Component. 


\section{Proposition 2a}

The written report identifies future development targets. - Manipulation

Component.

\section{Proposition $2 b$}

The written report considers future targets as a reflection of further CSR performance along with past performance. - Competence Components which will ultimately lead to future Performance.

It follows therefore that proposition (1b) follows logically from proposition (1a) and proposition (2b) follows logically from proposition (2a), essentially conceptualizing the components of the narrative schema discussed earlier: Manipulation or motivation (causingto-do); Competence (wanting-to-do or knowing-how-to-do) and Performance (having-to-do or being-able-to-do). Therefore for signification to occur proposition (1a) must be evident along with (1b) or at least implicit in one another. In addition, proposition (2a) must be evident along with (2b) or at least implicit in one another. Hence for the purpose of ontological classification the propositions are paired up such that the validity of each set of proposition is investigated under various world conditions by applying them to the contents of the CSR reports.

To apply the above propositions, we propose the following steps:

Phase 1: The first phase involved three steps;

Step 1: This step is to identify the semiotic act or acts - how many stories are told in each report? Each topic represents a semiotic act of social responsibility, thus a unit of analysis.

Step 2: This is to uncover the structural pattern of the narratives, that is to identify the modality of each semiotic of CSR as discussed earlier.

Step 3: This step is to examine each topic or unit of analysis by applying the four propositions above in order to determine the tonality of the characteristics observed in each story. The tonality refers to the veridictory characteristics of each story, which is denoted by the meta-terms (being, not-being, seeming, not-seeming). This is similar to examining whether or not a hypothesis was supported in a quantitative experiment.

Phase 2: This is the sanction phase. In this phase the outcome of step 3 above will subjected to further evaluation in order to examine the truth or falseness of the performance using the semiotic square of veridiction also called the Veridictory Square. It is a type of semiotic square built on the oppositions being and not-being or seeming and not-seeming and was developed by 
Greimas and Courtés (1982). Veridictory square is used to examine the extent of truth/falseness in any semiotic act where truth or falseness is fundamental to the whole analysis (Hébert, 2011).

Consequently since quality lies in the truth and authenticity of the performance reported, we considered the use of the semiotic square of veridiction as very relevant to this framework. The square will be adopted in the construction of our framework in order to determine the sanction components referred to in the semiotic schema above. It will be used in evaluating the reality, hence the reliability and quality of performance as claimed by the performing subject based on the characteristics of the features observed in the story from step 3 above. Basically the main elements of the Veridictory square are:

1. The subject - the narrator or author shown as ' $S$ ' on the square

2. The object - the act or performance shown as ' $\mathrm{O}$ ' on the square

3. The characteristics observed in the object shown as ' $\mathrm{C}$ ' on the square

4. The Veridictory status, which could be true, false, illusory or secret depending on the combination of the meta-terms (being, not-being, seeming or not-seeming) assigned to it in Phase1(step3), that is;
$\checkmark$ True (being + seeming),
$\checkmark$ False (not-being + not-seeming),
$\checkmark$ Illusory (not-being + seeming), and
$\checkmark$ Secret (being + not-seeming)

(Hébert, 2011:51-52)

This is illustrated diagrammatically below:

\section{Figure 6: The Semiotic Square of Veridiction}

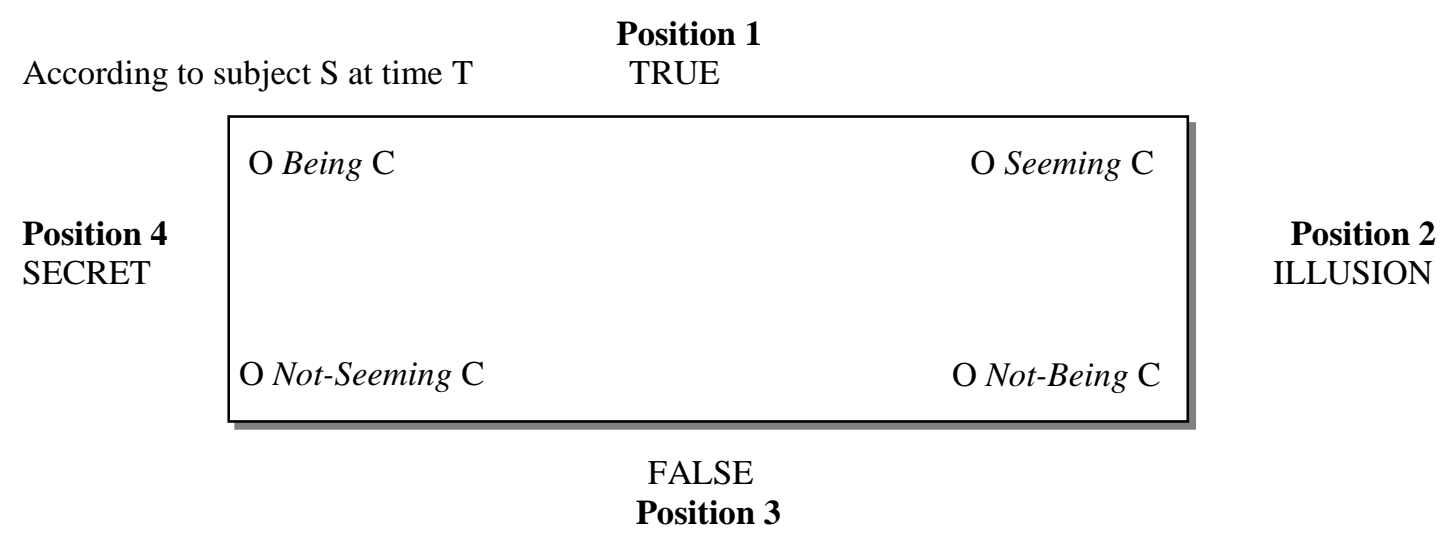

Legend: S: subject; O: object; C: characteristic; T: time-period

Source: Hébert, Louis (2011) "Tools for Text and Image Analysis: An Introduction to Applied Semiotics" Translated from the French version by Julie Tabler, version 3:2011, Page 54. 
In other words the story narrated by subject $\mathrm{S}$ in time $\mathrm{T}$ is assessed on the basis of the propositions and awarded a sanction or reward by assigning the Veridictory status - true, false, illusory or secret - depending on the combination of the meta-terms (being, not-being, seeming or not-seeming) assigned to it. See Figure 7 for a fuller description of the process.

\section{Figure 7: An overview of the Graimas CSRR-Quality Semiotic Framework}

\begin{tabular}{|c|c|c|c|c|c|}
\hline Time & $\begin{array}{l}\text { Unit of } \\
\text { Analysis }\end{array}$ & Procedure & Propositions & $\begin{array}{c}\text { Veridictory } \\
\text { status }\end{array}$ & $\begin{array}{c}\text { Ontological } \\
\text { Status }\end{array}$ \\
\hline $\mathrm{T} 1$ & $\begin{array}{l}\text { Specific } \\
\text { aspect of } \\
\text { CSR reports: } \\
\text { E.g. Health } \\
\text { and safety, } \\
\text { HR, } \\
\text { Community } \\
\text { Involvement } \\
\text { etc. }\end{array}$ & $\begin{array}{l}\text { Read each } \\
\text { topic/unit of } \\
\text { analysis and } \\
\text { check for } \\
\text { evidence of } \\
\text { P1a - P2b }\end{array}$ & $\begin{array}{l}\text { P1a: The written report on CSR } \\
\text { shows evidence of corporations, } \\
\text { concern or awareness of specific } \\
\text { needs or issues identified within their } \\
\text { community of operation. } \\
\text { P1b: The written report on CSR } \\
\text { shows evidence of the corporations } \\
\text { meeting the specific needs of the } \\
\text { community within their community of } \\
\text { operation. } \\
\text { P2a: The written report identifies } \\
\text { future targets. } \\
\text { P2b: The written report considers } \\
\text { future targets as a reflection of } \\
\text { further CSR performance along with } \\
\text { past performance. }\end{array}$ & $\left.\begin{array}{c}\text { Being } \\
\text { Seemingx } \\
\text { Being } \\
\text { Being }\end{array}\right\}$ True & $\begin{array}{c}\text { Real/ } \\
\text { Certainty }\end{array}$ \\
\hline
\end{tabular}

In Figure 7, we present an overview of the framework, illustrating how the components of the narrative schema Manipulation, Competence and Performance are conceptualized in the four propositions thus serving as a deep-structure schema. Similarly the Sanction component is conceptualized in the Veridictory/Ontological evaluation. Therefore, to construct reality, we seek to find evidence of the juxtaposition of both current CSR performance and future performance targets in a particular story. It follows that a particular CSRR should necessarily embrace all four propositions for signification to occur. In view of this, the analysis is designed to find a distinct spatial description that allows for the coexistence of two pairs of 
complementary meta-terms ${ }^{8}$ - being/seeming or seeming/being for the first set of propositions (1a \& 1b) and being/seeming or seeming/being for the second set of propositions ( $2 \mathrm{a}$ and $2 \mathrm{~b}$ ) such that the two pairs are awarded True Veridictory status as depicted in Figure 7. This allows both pairs to be placed in the same semantic universe and thus awarded a common ontological status. Therefore a story with veridictory status as depicted in Figure 7 can be said to be a true reflection of CSR performance and thus be awarded an ontological status of real.

However a change in time, say $\mathrm{T} 1$ to $\mathrm{T} 2$, may bring about a change in the position depicted in Figure 7. For instance in a scenario where a change in time from T1 to T2 leads to proposition (P2a) in Figure 7 being assigned a seeming characteristics and (P2b) being assigned not-being, the position for this pair of proposition will move on the Veridictory square to position 2 (Illusion). In this case the ontological status of such a semiotic act will be doubtful as far as CSR performance signification is concerned, because if the first set of propositions is true and the second set is a lie (i.e. illusion), then it is not clear if this is a real act of CSR or just a one-off event. For instance, a community involvement story considered as a semiotic act may only acquire the full ontological status of real (reality/certainty) when the Veridictory status of True is assigned to both pairs of propositions consistently through time.

\section{Summary and Conclusion}

In this chapter, we argue that reality might better be construed when the texts of CSRR are subjected to semiotic analysis. Therefore, given the mythological nature of the reports, we employ the Greimasian Canonical Narrative Schema in developing a framework, while the semiotic square of veridiction is used as an evaluative tool in determining the ontological status of each semiotic act. We develop propositional discourses following ideologies' form both the Preston (1975) and the Wood and Jones (1995) models.

We distinguished between the Barthesian and Greimasian semioticians and clearly explained our standpoint and why we took a position for the Greimas semiotics. The Barthes semiotics employs a purely paradigmatic approach while the Greimas semiotics employs the syntagmatic approach. The paradigmatic approach considers the system of signification, while

\footnotetext{
${ }^{8}$ The complementarities of the being and seeming meta-terms can be explained from the point of view of the relational values they possess, for instance for a being to exist, there must be a seeming in operation, either at the beginning, midway or at the end, which may or may not match its being, in other words, according to Hébert, (2011), "being is only an abstract reconstruction derived from seeming, which is the only accessible reality" (Hébert, 2011:51-52).
} 
the syntagmatic approach considers the process of signification. Nonetheless, though our analysis centres on the syntagmatic approach to semiotic analysis we embrace a bit of the paradigmatic paradigm in our analysis. The paradigmatic aspect of our analysis can be seen in the use of the opposing meta-terms being, not-being and seeming, not-seeming which determines the Veridictory status assigned to each pair of propositions when applied to the semiotic acts. The syntagmatic aspect of the analysis is the complete arrangement of all components into propositional combination, the collective presence of which constitutes signification. We ensured objectivity in our analysis by ignoring the institutional frameworks, and the social, economic and/or the political context within which the CSRR might have been produced and focus on how the CSRR as a semiotic sign can generate meanings from the perspective of the audience.

In our two-phase model, we address the ways in which each CSR activity reported can be examined based on evidence obtained from the organisation's CSR reports in relation to; the organisation's awareness of and concern for a need/an issue within their community of operation; the corporate action to actually meet the needs/issues identified; a demonstration of planned efforts for the future and Identifying links between past activities, present actions and future plans. We then assign values (veridictory status) to each evidence obtained to enable us determine the semiotic reality of the narratives. The strength of the value assigned, whether true, false, illusory or secret, based on the meta-terms being, not-being and seeming, notseeming determines our position.

For the purpose of quantitative research analysis such as regression and/or trend analysis, researchers can assign percentage values or scores to the veridictory status (true, false, illusory or secret) described above. This will produce a unique quality measure for measuring the quality of the content of CSRR. However, in addition to being a useful tool of analysis and measurement of quality, the framework is capable of guiding corporations in their CSR activities and reporting. It could also be useful to other stakeholders, particularly advocates and beneficiaries of CSR activities, such as the local community, to assess the reliability of corporations' claims to being socially responsible. The percentage value/scores can be used to facilitate trend analysis of the organisation's CSR performance. Such analysis can be useful to both the organisation and its stakeholders. While the former can use it to monitor its progress in CSR activities, the latter will be able to use it to make important economic and social decisions. 


\section{Bibliography}

Adams, C. A. (2004). The ethical, social and environmental reporting-performance portrayal gap. Accounting, Auditing and Accountability Journal, 17(5), 731 - 757.

Aras, G., \& Crowther, D. (2009). Corporate Sustainability Reporting: A Study in Disingenuity? Journal of Business Ethics, 87(S1), 279-288.

Barthes, R., (1967) “Elements of Semiology” Translated by Lavers, A. \& Smith, C., Jonathan Cape, London

Barthes, R., (1972), “Mythologies” Translated by Lavers, A., Jonathan Cape, London

Barthes, R., (1973), “The Pleasure of the Text” Translated by Le Seuil, Paris, Jonathan Cape, London

Barthes, R., \& Duisit, L. (1975). An Introduction to the Structural Analysis of Narrative. New Literary History, 6(2), 237-272.

Baudrillard, Jean (1988): Selected Writings (Ed. Mark Poster). Cambridge: Polity Press

Beattie, V., McInnes, B., \& Fearnley, S. (2004). A methodology for analysing and evaluating narratives in annual reports: a comprehensive descriptive profile and metrics for disclosure quality attributes. Accounting Forum, 28(3), 205-236.

Bebbington, J., Larrinaga-González, C., \& Moneva-Abadía, J. M. (2008). Corporate social reporting and reputation risk management. Accounting, Auditing \& Accountability Journal, 21(3), 337-361.

Belkaoui, A. (1978). Linguistic relativity in accounting. Accounting, Organizations and Society, 3(2), 97-104.

Belkaoui, A., (2004) “Accounting Theory” (5 ${ }^{\text {th }}$ Ed) Thomson Learning, Cornwall, UK

Bell, E., Taylor, S., \& Thorpe, R. (2002). Organizational differentiation through badging: investors in people and the value of the sign. Journal of Management Studies, 39(8), 1071-1085.

Beretta, S., \& Bozzolan, S. (2004). A framework for the analysis of firm risk communication. The International Journal of Accounting, 39(3), 265-288.

Beretta, S., \& Bozzolan, S. (2008). Quality Versus Quantity: The Case of Forward-Looking Disclosure. Journal of Accounting, Auditing and Finance, 23(3), 333.

Berger, A. A., (2005), "Media Analysis Techniques”, (3rd Ed) Thousand Oak, London: Sage, Pp. 3-36.

Billington, Rosamund (1991). Culture and society: A sociology of culture. Macmillan Education, London

Botosan, C. A. (2004). Discussion of a framework for the analysis of firm risk communication. The International Journal of Accounting, 39(3), 289-295. 
Burgh-Woodman, H. De, \& Brace-Govan, J. (2008). Jargon as imagining: Barthes' semiotics and excavating subcultural communication. Qualitative Market Research: An International Journal, 11(1), 89-106.

Burritt, R. L., \& Schaltegger, S. (2010). Sustainability accounting and reporting: fad or trend? Accounting, Auditing and Accountability Journal, 23(7), 829-846.

Buxton, David (1990) "From 'The Avengers' to 'Miami vice': Form and Ideology in Television Series”. Manchester: Manchester University Press

Chandler, D. (2007), Semiotics: The Basics. Routledge, London.

Cho, C. H., Roberts, R. W., \& Patten, D. M. (2010). The language of US corporate environmental disclosure. Accounting, Organisations and Society, 35(4), 431-443.

Chomsky, N., (1968) “Language and Mind” New York: Harcourt, Brace and World

Cooper, C., \& Puxty, A. (1994). Reading accounting writing. Accounting, Organizations and Society, 19(2), 127-146.

Cooper, M., Dimitrov, O., \& Rau, P. R. (2001). A rose.com by any other name. The Journal of Finance, 56(6), 2371-2388.

Cooper, S. M., \& Owen, D. (2007). Corporate social reporting and stakeholder accountability: The missing link. Accounting, Organizations and Society, 32(7-8), 649-667.

Corea, S. (2005). Refocusing Systems Analysis of Organizations Through a Semiotic Lens: Interpretive Framework and Method. Systemic Practice and Action Research, 18(4), $339-364$.

Crowther, D. (2002). A Social Critique of Corporate Reporting: A Semiotic Analysis of Corporate Financial and Environmental Reporting. Adlershot, England: Ashgate Publishing.

Crystal, David (1987): The Cambridge Encyclopaedia of Language. Cambridge: Cambridge University Press

Davison, J. (2007). Photographs and accountability: cracking the codes of an NGO. Accounting, Auditing \& Accountability Journal, 20(1), 133-158.

Davison, J. (2011). Barthesian perspectives on accounting communication and visual images of professional accountancy. Accounting, Auditing \& Accountability Journal, 24(2), $250-283$.

De Villiers C. and C.J. van Staden. (2010). Shareholders' requirements for corporate environmental disclosures: a cross-country comparison. British Accounting Review, 42(4), 227-240.

Eco, Umberto (1976), “A Theory of Semiotics” Bloomington, IN: University of Indiana Press.

Eco, Umberto (1994), “Apocalypse Postponed” (Ed. Robert Lumley) London:

BFI/Bloomington: Indiana University Press 
Feldman, M. S., Sköldberg, K., Brown, R. N., \& Horner, D. (2004). Making sense of stories: A rhetorical approach to narrative analysis. Journal of Public Administration Research and Theory, 14(2), 147-170.

Fiol, C. M. (1989). A Semiotic Analysis of Corporate Language: Organizational Boundaries and Joint Venturing. Administrative Science Quarterly, 34(2), 277.

Fiske, J., (1987): Television Culture. London: Routledge pp. 1-5

Floch, J.-M. (1988). 3.Floch 1988 - useful.pdf. International Journal of Research in Marketing, 4(1988), 233-252.

Freedman, M., \& Stagliano, A. J. (1992). European unification, accounting harmonization, and social disclosures. The International Journal of Accounting, 27(2), 112-122.

Freedman, M., \& Stagliano, A. J. (1995). Disclosure of environmental clean-up costs: The impact of the Superfund Act. Advances in Public Interest Accounting, 6, 163-176.

Freedman, M., \& Stagliano, A. J. (2008). Environmental disclosures: electric utilities and Phase 2 of the Clean Air Act. Critical Perspectives on Accounting, 19(4), 466-486.

Gilbert, K. R. (2002) "Taking A Narrative Approach To Grief Research: Finding Meaning In Stories. Death Studies, Brunner-Routledge, 26, 223-239.

Gray, R., Kouhy, R., \& Lavers, S. (1995). Constructing a research database of UK companies. Accounting , Auditing \& Accountability Journal, 8(2), 78-101.

Greimas, A. J. (1983): Structural Semantics. Lincoln, NB: University of Nebraska Press

Greimas, A. J. (1987). On meaning: Selected writings in semiotic theory. London: Frances Pinter.

Greimas, A. J., \& Courtés, J. (1982) Semiotics and language: An analytical dictionary, Bloomington: Indiana University Press

Gumperz, J. J., \& Levinson, S. C. (1996). Rethinking Linguistic Relativity. Cambridge:Cambridge Univ. Press.

Guthrie, J., \& Parker, L. D. (1990). Corporate social disclosure practice: a comparative international analysis. Advances in Public Interest Accounting, 3, 159-175.

Guthrie, J., Petty, R., Yongvanich, K., \& Ricceri, F. (2004). Using content analysis as a research method to inquire into intellectual capital reporting. Journal of Intellectual Capital, 5(2), 282-293.

Hackston, D., \& Milne, M. J. (1996). Some determinants of social and environmental disclosures in New Zealand companies. Accounting, Auditing \& Accountability Journal, 9(1), 77-108.

Hancock, P. (2006). The spatial and temporal mediation of social change. Journal of Organizational Change Management, 19(5), 619-639. 
Hasseldine, J., Salama, a. I. I., \& Toms, J. S. S. (2005). Quantity versus quality: the impact of environmental disclosures on the reputations of UK Plcs. The British Accounting Review, 37(2), 231-248.

Hawkes, T. (2004). Structuralism and Semiot ics (2nd ed.). New York: Routledge.

Hébert, Louis (2011) “Tools for Text and Image Analysis: An Introduction to Applied Semiotics" Translated from the French version by Julie Tabler, version 3:2011. Retrieved August 24, 2011 from http://www.signosemio.com/documents/Louis-HebertTools-for-Texts-and-Images.pdf

Ho, S. S. M., \& Wong, K. S. (2001). A study of the relationship between corporate governance structures and the extent of voluntary disclosure. Journal of International Accounting Auditing \& Taxation, 10, 139-156.

Hooks, J., \& van Staden, C. J. (2011). Evaluating environmental disclosures: The relationship between quality and extent measures. The British Accounting Review, 43(3), 200-213.

Jain, T. N. (1973). Alternative Methods of Accounting and Decision Making: A PsychoLinguistical Analysis. Accounting Review, 48(1), 95-104.

Jakobson, R. (1942). The paleosiberian languages. American Anthropologist, 66(6), 602-620.

Jakobson, Roman (1960): 'Closing Statement: Linguistics and Poetics'. In Sebeok (Ed.), op.cit, 350-377

Joutsenvirta, M. \& Uusitalo, L., (2010), “Cultural Competences: An Important Resource in the Industry-NGO Dialog”, Journal of Business Ethics, 91, 379-390

Kameda, N. (2005). A research paradigm for international business communication. Corporate Communications: An International Journal, 10(2), 168-182.

Kristeva, J. (1973). The Semiotic Activity. Screen, Oxford Journals.

Lévi-Strauss, Claude (1972): Structural Anthropology (translated by Claire Jacobson \& Brooke Grundfest Schoepf). Harmondsworth: Penguin

Lindblom, C. K. \& Ruland, R. G., (1997) "Functionalist and Conflict Views of AICPA Code of Conduct: Public Interest vs. Self Interest.” Journal of Business Ethics 16, 573-582

Lucy, J. A. (1992). Language Diversity and Thought: A Reformulation of the Linguistic Relativity Hypothesis. Cambridge Univ. Press.

Lucy, J. A. (1997). Linguistic Relativity. Annual Review of Anthropology, 26(1), 291-312.

Macintosh, N. B. (2003). From rationality to hyperreality: paradigm poker. International Review of Financial Analysis, 12(4), 453-465. 
Macintosh, N.B. and Baker, C.R. (2002), "A literary theory perspective on accounting: towards heteroglossic accounting reports", Accounting, Auditing \& Accountability Journal, 15(2), 184-222

Macintosh, N. B., Shearer, T., Thornton, D. B., \& Welker, M. (2000). Accounting as simulacrum and hyperreality: perspectives on income and capital. Accounting, Organizations and Society, 25(1), 13-50.

Maddox, D. (1989). Veridiction, Verifiction, Verifactions: Reflections on Methodology. New Literary History, 20(3), Greimassian Semiotics (Springer, 1989), 661-677.

McGoun, E. G., Bettner, M. S., \& Coyne, M. P. (2007). Pedagogic metaphors and the nature of accounting signification. Critical Perspectives on Accounting, 18(2), 213-230.

Morris, C. W. (1946): Signs, Language and Behaviour. New York: Prentice-Hall

Otubanjo, B. O., \& Melewar, T. C. (2007). Understanding the meaning of corporate identity: a conceptual and semiological approach. Corporate Communications: An International Journal, 12(4), 414-432.

Peirce, Charles Sanders (1931-58): Collected Writings (8 Vols.). (Ed. Charles Hartshorne, Paul Weiss \& Arthur W Burks). Cambridge, MA: Harvard University Press

Preston, L. E. (1975). Corporation and Society: The Search for a Paradigm. Journal of Economic Literature, XIII(June), 434-453.

Preston, L. E., and Post, J. E. (1975). Private Management and Public Policy: The principle of public responsibilty. Englewood Cliffs, New Jersey, Prentice Hall.

Price, R., \& Shanks, G. (2005). A semiotic information quality framework: development and comparative analysis. Journal of Information Technology, 20(2), 88-102.

Propp, Vladimir I (1958): Morphology of the Folktale (trans. Laurence Scott, 2nd Ed.). Austin: University of Texas Press

Saussure, Ferdinand de (1983): Course in General Linguistics (trans. Roy Harris). London: Duckworth

Sebeok, Thomas A. (1977): A Perfusion of Signs. Bloomington: Indiana University Press

Sebeok, Thomas A. (1994): An Introduction to Semiotics. London: Pinter [an introduction to Thomas Sebeok]

Slater D., (1997) Consumer Culture and Modernity Cambridge: Polity Press

Sulkunen, P., \& Törrönen, J. (1997). The Production of values: The concept of modality in textual discourse analysis. Semiotica, 113(1/2), 43-69. 
Toms, J. S. (2002). Firm Resources, Quality Signals and the Determinants of Corporate Environmental Reputation: Some Uk Evidence. The British Accounting Review, 34(3), 257-282.

Walden, W. D., \& Schwartz, B. N. (1997). Environmental Disclosures and Public Policy Pressure. Journal of Accounting and Public Policy, 16, 125-154.

Wood, D. J., \& Jones, R. E. (1995). Stakeholder Mismatching: A Theoretical Problem in Empirical Research on Corporate Social Performance. The International Journal of Organizational Analysis, 3(3), 229-267.

Yekini, K. C., Adelopo, I., Andrikopoulos, P., \& Yekini, S. (2015). Impact of board independence on the quality of community disclosures in annual reports. Accounting Forum, online first.

Yekini, K., \& Jallow, K. (2012). Corporate community involvement disclosures in annual report: A measure of corporate community development or a signal of CSR observance? Sustainability Accounting, Management and Policy Journal, 3(1), 7-32.

Yusoff, H., \& Lehman, G. (2009). Corporate environmental reporting through the lens of semiotics. Asian Review of Accounting, 17(3), 226-246.

\section{Biography of author}

Dr Kemi Yekini's many years of experience in professional practice and industry has largely driven her teaching and research interest(s), which can be grouped around accountability and transparency in corporate disclosure practices. Kemi has developed a broad approach to examining CSR and sustainability reporting and other narrative company disclosures, to assess the accountability to these issues of the large multi-nationals. She interprets CSR to encompass many aspects of social and environmental interactions and has a particular interest in understanding firm's interaction with its corporate and extended environment through highquality disclosures. Her research interest encompasses CSR communication, sustainability and accountability, auditing, corporate governance and forensic accounting. She currently supervises doctoral students within these research areas. Kemi is the Editor of the Accounting and Finance Occasional Paper Series of the De Montfort University and the director of the Centre for Research into Accountability, Governance and Sustainability (CRAGS). Dr Kemi Yekini is the corresponding author and can be contacted at: kyekini@dmu.ac.uk 